\title{
ANÁLISE DOS ESTÁGIOS DE SUCESSÃo DE ÁREAS DE MATA ATLÂNTICA SOB A INFLUÊNCIA DE PLANTAÇÕES FLORESTAIS, VALE DO RIO DOCE, MINAS GERAIS, BRASIL ${ }^{1}$
}

\author{
Jacinto Moreira de Lana², Agostinho Lopes de Souza ${ }^{3}$, João Augusto Alves Meira Neto ${ }^{3}$, Vicente \\ Paulo Soares ${ }^{3}$ e Elpídio Inácio Fernandes Filho ${ }^{3}$
}

\begin{abstract}
RESUMO - Este trabalho teve como objetivos mapear e classificar as áreas preservadas num projeto de base florestal. Foram classificadas, na região do Médio Vale do Rio Doce, no Leste do Estado de Minas Gerais, duas áreas com cobertura florestal nativa e plantações de eucalipto: Área de Cocais (região montanhosa) e Área de Ipaba (região de baixadas). Foram utilizados mapas, técnicas de interpretação visual de ortofotocartas, levantamentos de campo e análise de documentos sobre as áreas estudadas. A classificação dos estágios de sucessão seguiu os parâmetros estabelecidos na Resolução No 10 do CONAMA, de $1^{\circ}$ de outubro de 1993. Foram elaborados diagramas de perfis verticais dos estádios de sucessão florestal e demais tipos vegetais mapeados nas áreas de estudo. Na região montanhosa sobressaíram, em área, os estágios inicial (52\%) e médio (31\%) e na região de baixadas, os estágios médio (33\%) e inicial (23\%). Nas regiões de montanhas e de baixadas, os fragmentos pequenos ( $\leq 5 \mathrm{ha}$ ), em maior número (69\%), contribuíram com apenas 10\% (2.462 ha) da área total preservada na região montanhosa e 6\% (2.907 ha) na região de baixadas. Os fragmentos com mais de 50 ha, em menor número, com menos de 5\%, contribuíram com 53\% da área total dos fragmentos florestais na região montanhosa e com $67 \%$ na região de baixadas, indicando, em ambas, alta conectividade entre fragmentos.
\end{abstract}

Palavras-chave: Floresta Atlântica, Estágios de sucessão, Ecologia de paisagem e Classificação de vegetação.

\section{ANALYSIS OF THE SUCCESSIONAL STAGES OF THE ATLANTIC FOREST IN AREAS UNDER THE INFLUENCE OF FORESTRY PLANTATIONS, VALE DO RIO DOCE, STATE OF MINAS GERAIS, BRAZIL}

\begin{abstract}
The objectives of this work were to map and classify the preserved areas in a forestry based project. In the region of the medium Vale do Rio Doce, located in the Eastern part of the State of Minas Gerais, two areas with native forest cover and eucalypt plantings were classified as follows: Areas of "Cocais" (hilly region) and Areas of "Ipaba" (lowland region). Maps, techniques of visual interpretation of orthophotocharts, field surveys and analyses of documents of the areas studied were used. The classification of the successional stages followed the parameters established in the No 10 Resolution of CONAMA, of October 1st, 1993. Diagrams of vertical profiles of the forest successional stages and those of the other plant types mapped in the area studied were made. In the hilly region the initial (52\%) and medium (31\%) stages were the major ones in the area. And in the lowland region, the medium (33\%) and initial (23\%) stages were in the majority. Both in the hilly and in the lowland region the small fragments ( $\leq 5$ ha in greatest number $69 \%$ ) contributed to only $10 \%$ (2,462 ha) of the total preserved area in the hilly region, and 6\% (2,907 ha) in the lowland region. The large fragments, with more than $50 \mathrm{ha}$, with the smallest number, less than $5 \%$, contributed to $53 \%$ of the total preserved area in the hilly region and with $67 \%$ in the lowland region, indicating, in both cases, a high connectivity among fragments.
\end{abstract}

Keywords: Atlantic Forest, Successional stages, Landscape ecology and Vegetation classification.

\footnotetext{
${ }^{1}$ Recebido em 04.07.2008 e aceito para publicação em 02.03.2010.

${ }^{2}$ Celulose Nipo-Brasileira SA - CENIBRA. E-mail: <jacinto.lana@cenibra.com.br>.

${ }^{3}$ Universidade Federal de Viçosa, Brasil. E-mail: <alsouza@ufv.br>, <j.meira@ufv.br>, <vicente@ufv.br>e <elpidio@ufv.br>.
} 


\section{INTRODUÇÃO}

Desde os primórdios do domínio dos ecossistemas naturais pelas populações de Homo sapiens que a ocupação antrópica vem causando contínuos distúrbios aos ecossistemas naturais (CAIRNS JR., 2004). A fragmentação de ecossistemas florestais figura na lista dos impactos humanos sobre o ambiente (BROWN et al., 2002) e é citada no artigo sobre sustentabilidade e alteração antropogênica dos processos evolucionários (CAIRNS JR., 2004).

Em geral, a gestão ambiental das propriedades agrícolas e pecuárias ainda carece de estratégias conjuntas de ações ambientais. Nas propriedades de empresas florestais, as paisagens já mostram nítidas diferenças, porque os projetos de reflorestamento dependem de licenciamento ambiental (BRASIL, 1981; MINAS GERAIS, 2004). Os processos de licenciamento preveem a necessidade de recuperar e conservar as áreas de reservas, o que também está evidenciado na certificação do manejo das plantações florestais.

Na gestão dos empreendimentos de base florestal, a cobertura vegetal natural, representada pelas áreas de reservas ou fragmentos, deve ser analisada por bioma (PONZONI e RESENDE, 2002), por tipologia vegetal (VELOSO et al., 1991; e IBGE, 2004) e por estágio de sucessão ou de regeneração (BRASIL, 1993, 2007).

Cada fragmento deve ser analisado pelas seguintes variáveis: classes de tamanhos, forma, grau de isolamento ou de conectividade, posição no relevo, exposição solar e tipo de vizinhança (MARTINS et al., 2002; NASCIMENTO et al., 2006; OLIVEIRA et al., 1997). A análise conjunta das variáveis permite: conhecer os tipos vegetais, estágios de sucessão, distribuição espacial por estágio de sucessão e por classe de tamanho; caracterizar a paisagem; visualizar a matriz de usos do solo; inferir acerca do estado de conservação geral de uma região; e fundamentar a elaboração e execução de uma estratégia de conservação ambiental.

Os resultados podem fundamentar: inventários para estudos de composição florística e de estrutura fitossociológica (ESPÍRITO-SANTO et al., 2005); inventários de dinâmica de sucessão, crescimento e produção florestal (FERREIRA et al., 1999; SOUZA et al., 2002); inventários para avaliar estoques e dinâmica de biomassa e carbono em áreas de reservas florestais; projetos de reintrodução de fauna e restauração ambiental
(BATISTELLA, 2003); manejo de paisagem (METZGER, 1999); educação e proteção ambiental; estabelecimento de áreas prioritárias para conservação e florestas de alto valor para conservação (HIGMAN et al., 2005); averbações e adequações de áreas de reserva legal e de preservação permanente; e apoiar os programas de certificação de sistemas de produção florestal, agropecuário e agroenergético.

Este estudo teve como objetivo analisar os estágios de sucessão da vegetação secundária em áreas de preservação permanente e reserva legal num projeto de base florestal.

\section{MATERIAL E MÉTODOS}

\section{1. Área de estudo}

Este estudo foi realizado em 2006, em duas regiões de atuação da CENIBRA S.A.: Cocais e Ipaba, Vale do Rio Doce, MG (Figura 1). Cocais é região de montanhas (750 a 1.100 m) e Ipaba, de baixadas (220 a 300 m), isto é, áreas com relevo suave-ondulado e mais baixas (LANA, 2006).

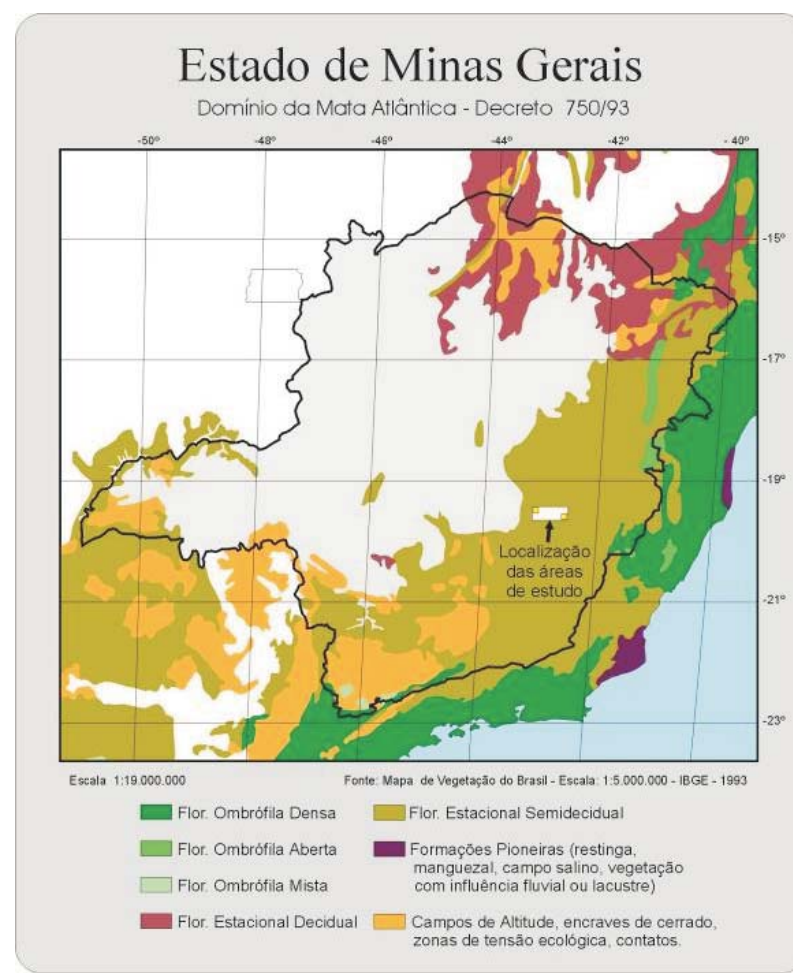

Figura 1 - Mapa mostrando as áreas de estudo e as tipologias da Mata Atlântica no Estado de Minas Gerais.

Figure 1 - Map showing the study areas and the vegetation type of the Atlantic Forest in the State of Minas Gerais. 
A região de Cocais está situada nos Municípios de Coronel Fabriciano e Antônio Dias (coordenadas UTM - Unidade Transversal de Mercador, fuso 23: 722.000N, 7.844.000E, 730.00Ne 7.852.000E). Atipologia vegetal pertence à região fitoecológica da Floresta Estacional Semidecidual Montana (VELOSO et al., 1991). Segundo a classificação climática de Köppen, o clima predominante é o Cwb. A temperatura máxima $\left(28,2^{\circ} \mathrm{C}\right)$ ocorre nos meses de fevereiro e março, e a mínima $\left(9,7^{\circ} \mathrm{C}\right)$ dá-se no mês de agosto. A umidade relativa média do ar é de 65,4\%. A precipitação pluviométrica média mensal é de 106,6 mm, sendo a máxima no mês de dezembro e a mínima no mês de junho, conforme registro da Estação Meteorológica de Antônio Dias (longitude oeste 42 $2^{\circ}$ 51', latitude sul $19^{\circ} 27^{\prime}$ e altitude 950 m) (LANA, 2006).

A região de Ipaba está situada nos Municípios de Caratinga e Bom Jesus do Galho, entre as coordenadas UTM: 764.000N, 7.834.000E, 772.000N e 7.842.000E. A tipologia vegetal original pertence à região fitoecológica da Floresta Estacional Semidecidual Submontana (VELOSO et al., 1991). O clima predominante, segundo a classificação climática de Köppen, é o Aw. A temperatura máxima $\left(34,4^{\circ} \mathrm{C}\right)$ ocorre no mês de fevereiro e, a mínima $\left(15,4^{\circ} \mathrm{C}\right)$, nos meses de julho e agosto. A umidade relativa média é de 59,8\%. A precipitação pluviométrica média mensal é de 106,6 mm, sendo a máxima no mês de dezembro e a mínima no mês de julho, conforme registro da Estação
Meteorológica do Viveiro Florestal, Município de Belo Oriente, MG (longitude oeste $42^{\circ} 23^{\prime}$, latitude sul $19^{\circ} 17^{\prime}$ e altitude $214 \mathrm{~m}$ ) (ECOA, 2002).

Nas duas regionais são cultivados eucaliptos há aproximadamente 50 anos. Em ambas, cerca de 40\% das áreas estão protegidas (reserva legal e preservação permanente), $10 \%$ ocupadas com infraestruturas (estradas, aceiros, linhas de transmissão de energia etc.) e cerca de $50 \%$ são cultivadas com eucaliptos.

\subsection{Classificação dos estágios de sucessão}

\subsubsection{Base legal da classificação}

As áreas protegidas foram classificadas nos estágios de sucessão inicial, médio e avançado (BRASIL,1993), conforme parâmetros: estratos predominantes; distribuições de diâmetros e de alturas; existência, diversidade e quantidade de epífitas e trepadeiras; presença, ausência e características da serapilheira e sub-bosque; diversidade e dominância de espécies; e presença de espécies vegetais indicadoras. Os parâmetros e critérios de classificação das tipologias vegetais não contemplados pela Resolução $\mathrm{n}^{\circ} 10$ do CONAMA (BRASIL,1993) foram estabelecidos com base em análises ecológicas em campo, sendo identificadas e definidas, no total, oito classes de informação (Tabela 1).

Tabela 1 - Classes de informação das tipologias vegetais mapeadas nas áreas de estudo, Cocais e Ipaba, região Leste do Estado de Minas Gerais.

Table 1 - Information classes of the vegetable typologies mapped in the areas studied, Cocais and Ipaba, Vale do Rio Doce, State of Minas Gerais, Brazil, 2006.

\begin{tabular}{|c|c|}
\hline Classes de informação & Descrição \\
\hline Áreas abertas (AA) & $\begin{array}{l}\text { Áreas com cobertura vegetal herbácea e arbustiva, desprovidas de vegetação de } \\
\text { porte arbóreo. }\end{array}$ \\
\hline Áreas arborizadas (AB) & $\begin{array}{l}\text { Áreas com vegetação arbórea esparsa, com cobertura vegetal herbáceo/arbustiva } \\
\text { e com indivíduos arbóreos presentes em baixa densidade. }\end{array}$ \\
\hline Afloramentos rochosos (AR) & $\begin{array}{l}\text { Áreas com vegetação herbácea e arbustiva sobre rocha. Campos de altitude, ou } \\
\text { vegetação instalada sobre afloramentos de rochas. }\end{array}$ \\
\hline Áreas alagadas (AL) & $\begin{array}{l}\text { Áreas com vegetação sobre solo encharcado. Ambientes alagados, onde predominam } \\
\text { principalmente espécies macrófitas. }\end{array}$ \\
\hline Eucalipto e espécies nativas (EN) & $\begin{array}{l}\text { Áreas preservadas com árvores de eucalipto remanescentes de antigas plantações, } \\
\text { com ou sem regeneração de sub-bosque. }\end{array}$ \\
\hline Estágio inicial (EI) & $\begin{array}{l}\text { Áreas com cobertura vegetal, formando um dossel arbóreo contínuo, de pequeno } \\
\text { porte, com baixa diversidade florística e predomínio de espécies pioneiras. Geralmente } \\
\text { apresenta infestação de cipós. }\end{array}$ \\
\hline Estágio médio (EM) & $\begin{array}{l}\text { Áreas com cobertura vegetal arbórea de porte mais desenvolvido, onde já sobressaem } \\
\text { algumas árvores dominantes ou emergentes. Há maior diversidade de espécies } \\
\text { arbóreas, em relação ao estágio inicial. }\end{array}$ \\
\hline Estágio avançado/clímax (EA) & $\begin{array}{l}\text { Áreas com cobertura vegetal arbórea muito desenvolvida. Destacam-se, principalmente, } \\
\text { as árvores de grande porte, a nítida diferenciação de extratos verticais e a elevada } \\
\text { diversidade de espécies arbóreas. }\end{array}$ \\
\hline
\end{tabular}




\subsubsection{Análise dos estágios de sucessão}

O mapeamento e classificação da cobertura vegetal compreenderam as regiões de Cocais e Ipaba, cada uma com 6.400 ha. Foram utilizados mapas, técnicas de interpretação visual de ortofotocartas, levantamentos de campo e análise de documentos sobre as áreas de estudo. Como base cartográfica foram utilizadas folhas topográficas na escala de 1:10.000 e ortofotocartas com datas de voo de 1986 na escala de 1:10.000 (CEMIG 1986).

A primeira etapa consistiu na transferência dos limites das áreas de reservas para as ortofotocartas, mediante a sobreposição destas nos respectivos mapas planialtimétricos das áreas de estudo. Na segunda etapa, foram realizadas análises ecológicas rápidas (SAYRE et al., 2003) nas áreas de estudo, para verificação da existência dos estágios de sucessão (BRASIL, 1993) e das demais classes de informação. Os padrões de referência (Figura 2), elaborados com base em cobertura,
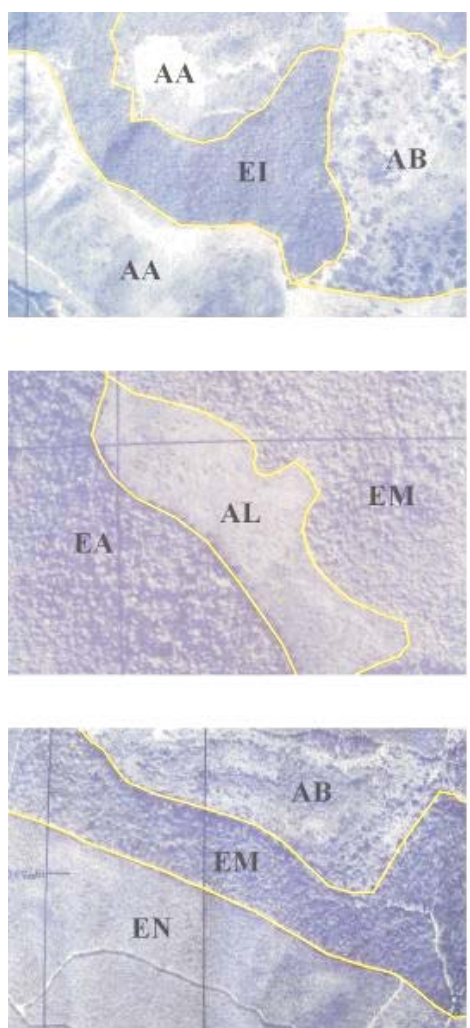

textura e tonalidades de copas, foram ilustrados em diagramas de perfil idealizados (Figuras 3 e 4). Para estabelecer os parâmetro especificados na Resolução $\mathrm{n}^{\circ} 10$ do CONAMA (BRASIL, 1993) foram realizados inventários diagnósticos em trechos representativos das classes de informação. A terceira etapa consistiu na realização da classificação, no laboratório, dos estágios de sucessão, utilizando as ortofotocartas e os gabaritos. Na quarta etapa foi realizada, em campo, a checagem das classificações efetuadas no laboratório, com o objetivo de confirmar a fidedignidade das informações, realizando as correções necessárias para a elaboração do mapa final. Na sexta etapa, os perímetros dos polígonos foram digitalizados em mesa digitalizadora, transferidos para o modulo ArcMap ${ }^{1}$, software ArGIS (ESRI, 2004), quando foram medidas as áreas. Os dados foram tabulados e analisados por estágio de sucessão e, por fim, foram calculadas as classes de tamanho das áreas de reservas.
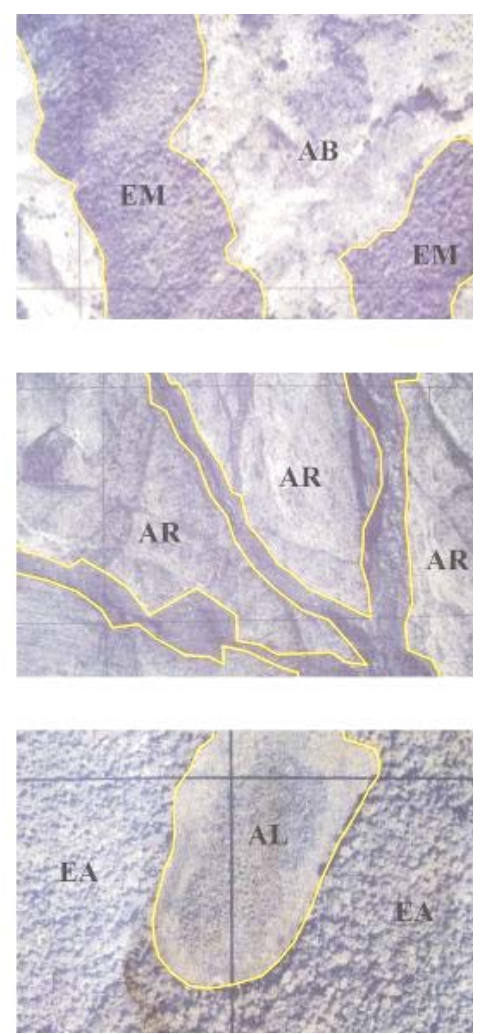

Figura 2 - Segmentos de ortofotocarta mostrando as diferentes texturas dos estágios de regeneração da vegetação, em que: $\mathrm{AA}$ = área aberta, $\mathrm{AB}$ = área arborizada, $\mathrm{AL}$ = área alagada, $\mathrm{AR}=$ afloramento rochoso, $\mathrm{EN}$ = eucalipto + nativas, $\mathrm{EI}$ = estágio inicial, EM = estágio médio e EA = estágio avançado.

Figure 2 - Ortophotochart segments showing the different textures of the vegetation regeneration stages, in which: $A A=$ open area; $A B=$ arborized area; $A L=$ flooded area; $A R=$ rocky emergencies; $E N=$ eucalypt + native trees; $E I=$ initial stage $E M=$ medium stage and $E A=$ advanced stage .

Revista Árvore, Viçosa-MG, v.34, n.4, p.733-743, 2010 

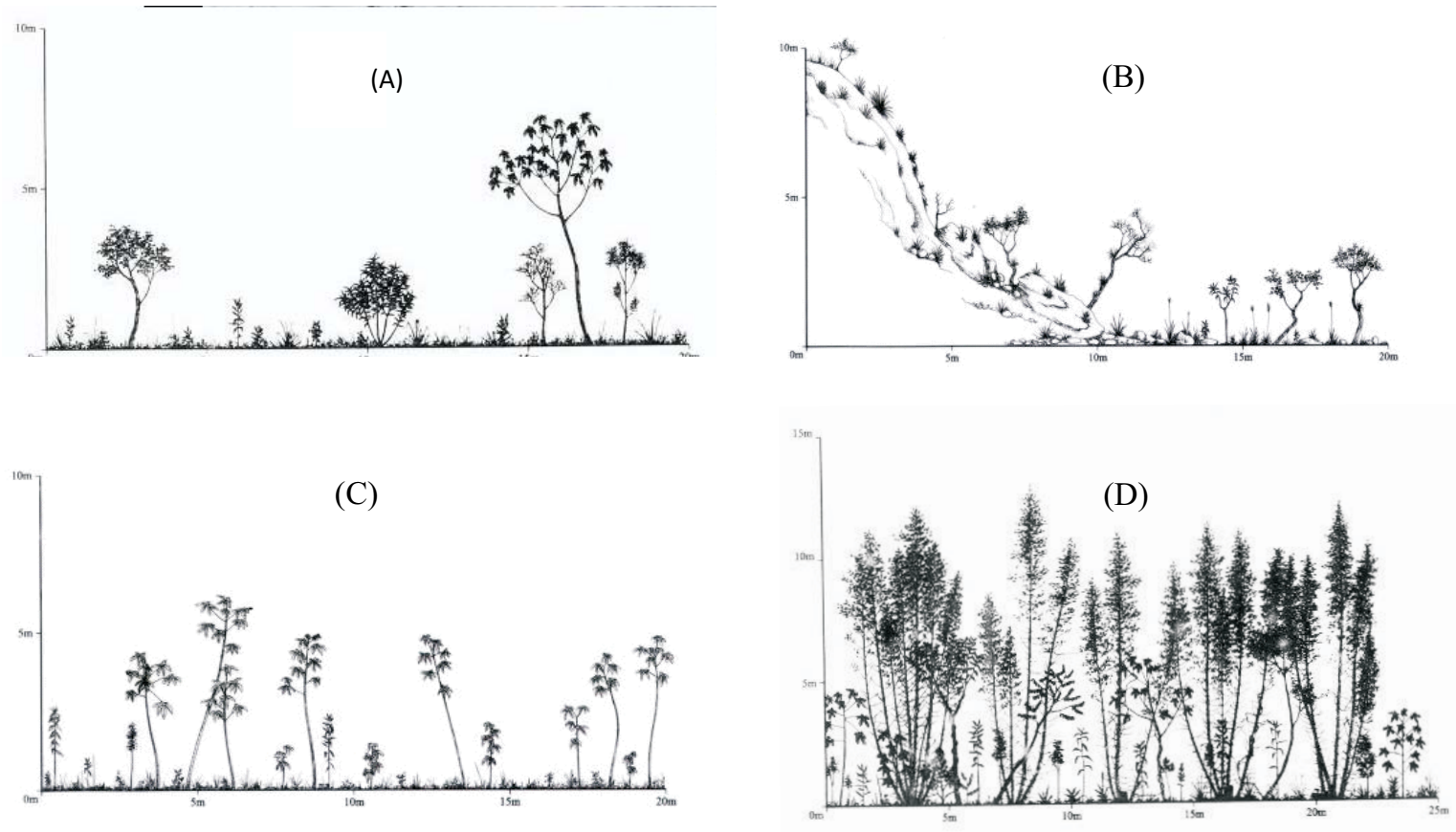

(E)
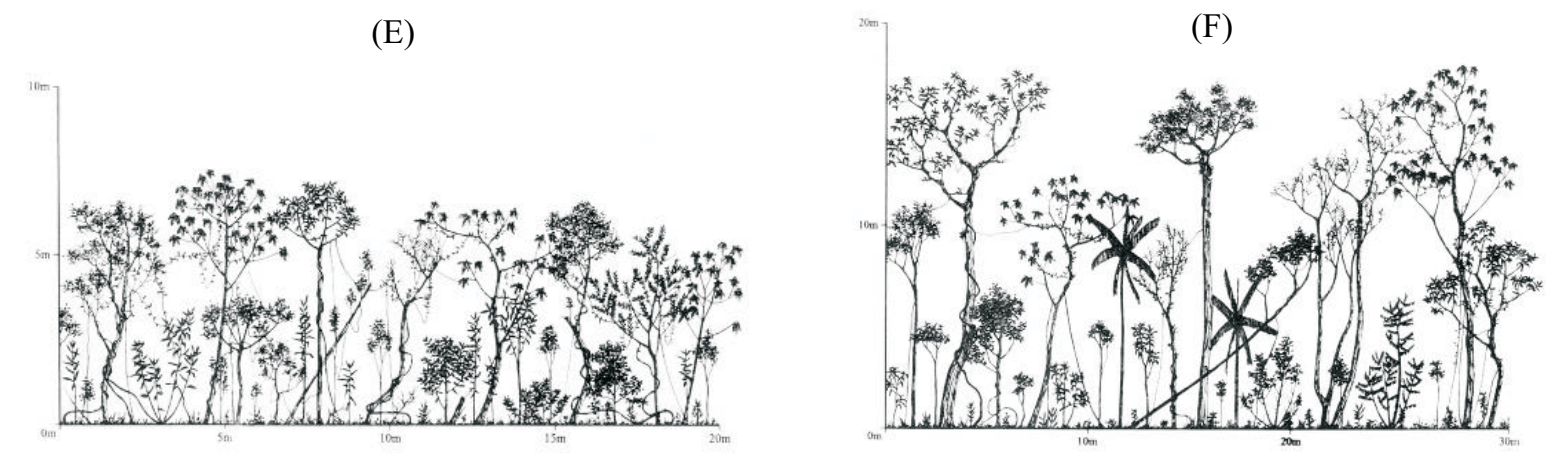

Figura 3 - Ilustração de perfil representativo da cobertura vegetal: (A) área arborizada, que é definida como início de sucessão florestal secundária onde ocorrem espécies arbóreas pioneiras em área de campo antrópico com vegetação herbácea. (B) Afloramento rochoso, onde predominam espécies herbáceas e arbustivas. (C) Áreas alagadas, onde predominam espécies herbáceas, arbustivas e, eventualmente, árvores de Cecropia sp. (D) Eucalipto com sub-bosque de vegetação nativa autóctone. Esta classe de área preservada consiste de antigos talhões que foram destinados para compor áreas de reserva legal ou áreas de preservação permanente. (E) Estágio inicial de regeneração, onde se notam: infestação de cipós; alturas totais das árvores menores que 10 m; e dossel superior em mesma classe de altura. (F) Estágio médio de regeneração, onde se notam: altura das árvores do dossel superior entre 10 e 20 m, início de diferenciação de estratos na estrutura vertical, aparecimento de espécies epífitas e diminuição da infestação de cipós.

Figure 3 - Illustration of a representative profile of the vegetation cover called: (A) arborized area, defined as the beginning of the secondary forest succession, where the pioneer tree species occur in anthropic prairie areas with herbaceous vegetation; (B) rocky emergencies, where herbaceous and shrubby species predominate; (C) flooded areas, where herbaceous, shrubby and Cecropia sp: trees species predominate; (D) eucalypt with an understorey of native autotoctonous vegetation. This class of preserved area consists of old stands that were destined to compose legal reserve areas or permanent preservation areas; (E) initial stage of regeneration, where vine infestation, total heights of the trees less than 10 meters and the higher canopy in the same height class were observed; and $(F)$ medium stage of regeneration, where tree height of the higher canopy from 10 to 20 meters; beginning of differentiation of strata in the vertical structure; existence of epiphyt species and the reduction of vine infestation were observed. 


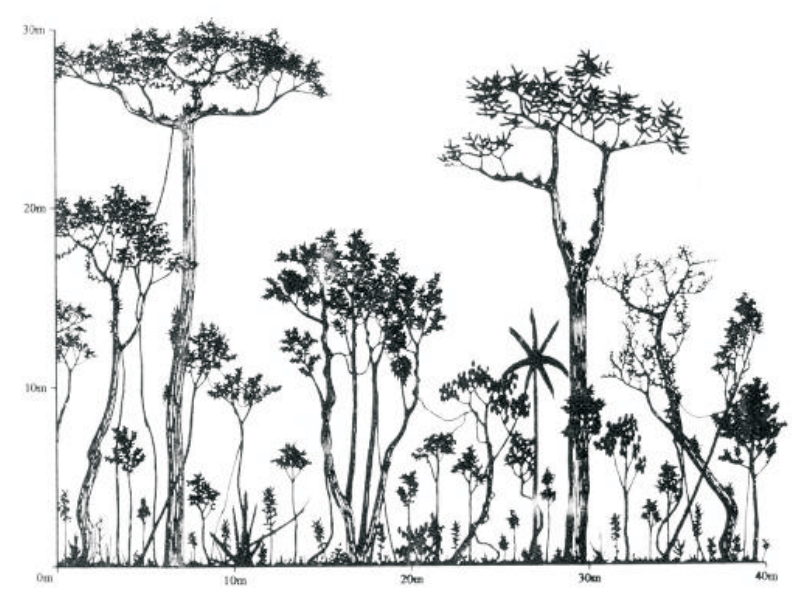

Figura 4 - Ilustração de perfil representativo da cobertura vegetal denominada estágio avançado de regeneração, onde se notam: altura das árvores do dossel atingindo 30 m, grande diferenciação de estratos verticais, presença de espécies epífitas e pouca infestação de cipós.

Figure 4-Illustration of a representative profile of the vegetation cover called advanced regeneration stage, where: height of the canopy trees reaching 30 meters; great differentiation in the vertical strata; presence of epiphyt species and little vine infestation were observed.

\section{RESULTADOS E DISCUSSÃO}

\subsection{Diagramas de perfil}

Os diagramas de perfis foram úteis na análise dos estágios de sucessão das áreas de reservas naturais, conferindo rapidez e precisão na identificação das classes de informação (Tabela 1) em campo e a expressão visual dos parâmetros classificatórios.

A classe denominada área arborizada definiu o início de sucessão florestal secundária, onde ocorreram espécies arbóreas pioneiras associadas com vegetação herbácea em área de campo com uso antrópico (Figura 3A), e nos afloramentos rochosos predominaram espécies herbáceas e arbustivas (Figura 3B).

Nas áreas alagadas, formações naturais comuns na área de baixadas (área de Ipaba) predominaram espécies herbáceas, arbustivas e árvores de Cecropia sp. (Figura 3C).

As áreas de eucalipto com espécies nativas resultaram da exclusão de áreas com eucaliptos do conjunto de áreas de floresta de produção, em que, com o decorrer do tempo, os processos de dinâmica de regeneração natural formaram sub-bosque com espécies herbáceas, arbustivas e arbóreas (Figura 3D).

Os estágios de sucessão da vegetação secundária foram caracterizados assim: estágio inicial - alta infestação de cipós, altura total das árvores menor que 10 m e único dossel na mesma classe de altura (Figura 3E); estágio médio - alturas das árvores do único dossel entre 10 e 20 m, início de diferenciação em estratos verticais, aparecimento de epífitas e diminuição da infestação de cipós (Figura 3F); e estágio avançado - altura das árvores emergentes atingindo até $30 \mathrm{~m}$, diferenciação de estratos verticais, presença de espécies epífitas e pouca infestação de cipós, porém cipós lenhosos (Figura 4).

\subsection{Classificação dos estágios de sucessão}

Na região montanhosa (Cocais), o estágio inicial e o estágio médio de sucessão totalizaram 52\% e 31\%, respectivamente, do número total de áreas preservadas (Tabela 2). Na região de baixadas (Ipaba), destacaram (Tabela 2) os estágios médio (33\%), eucalipto com espécies nativas (25\%), estágio inicial (23\%) e áreas alagadas (12\%).

Os resultados da área montanhosa apresentaram relação com o histórico do uso do solo regional, que foi ocupado, principalmente, pela pecuária antes da atividade silvicultural. As maiores proporções de áreas abertas e de áreas arborizadas são evidências do uso do solo para pastoreio, há cerca de 20 anos. Já as áreas com “eucalipto e espécies nativas (EN)" na baixada são consequências da adequação do uso legal do solo para plantações florestais, que se iniciaram há mais de 50 anos. As antigas plantações ocupavam praticamente todas as áreas de baixada com solos cultiváveis, e a adequação ambiental de áreas de reserva legal e de preservação permanente ainda não promoveu a reversão total dos povoamentos de eucalipto para floresta nativa. Essas áreas apresentam sub-bosque com diversidade de espécies nativas, estrutura fitossociológica e estágios de desenvolvimento semelhantes a outras áreas de matas nativas em estágio de regeneração da vegetação secundária na região (CALEGARIO et al., 1993; SOUZA et al., 2007). Essas reservas estão sendo revertidas para florestas nativas por meio da sucessão da vegetação secundária e medidas de recuperação ambiental, que têm a supressão das árvores de eucalipto e a condução e monitoramento da regeneração natural como principais ações de manejo. 
Tabela 2 - Resultados da classificação, por estágio de sucessão, da cobertura vegetal das áreas preservadas em Cocais e Ipaba, Vale do Rio Doce, Estado de Minas Gerais, Brasil, 2006.

Table 2 - Results of the classification, by succession stages, of the vegetatation cover of the preserved areas included in the areas studied in Cocais and Ipaba, Vale do Rio Doce, State of Minas Gerais, Brazil, 2006.

\begin{tabular}{|c|c|c|c|c|c|c|}
\hline \multirow[t]{2}{*}{ Classes de Áreas Preservadas } & \multicolumn{2}{|c|}{ Cocais } & \multicolumn{2}{|c|}{ Ipaba } & \multicolumn{2}{|c|}{ Total } \\
\hline & Área (ha) & $\%$ & Área (ha) & $\%$ & Área (ha) & $\%$ \\
\hline Área aberta (AA) & 55,74 & 2,3 & 33,10 & 1,1 & 88,84 & $\overline{1,7}$ \\
\hline Área arborizada (AB) & 116,24 & 4,7 & 49,35 & 1,7 & 165,59 & 3,1 \\
\hline Área alagada (AL) & 0,00 & 0,0 & 350,14 & 12,0 & 350,14 & 6,5 \\
\hline Afloramento rochoso (AR) & 44,15 & 1,8 & 0,00 & 0,0 & 44,15 & 0,8 \\
\hline Eucalipto + nativas (EN) & 115,90 & 4,7 & 734,62 & 25,3 & 850,52 & 15,8 \\
\hline Estágio inicial (EI) & $1.278,24$ & 51,9 & 657,91 & 22,6 & $1.936,15$ & 36,1 \\
\hline Estágio médio (EM) & 769,29 & 31,2 & 970,12 & 33,4 & $1.739,41$ & 32,4 \\
\hline Estágio avançado (EA) & 82,59 & 3,4 & 111,96 & 3,9 & 194,55 & 3,6 \\
\hline Total & $2.462,15$ & 100 & $2.907,20$ & 100 & $5.369,35$ & 100 \\
\hline
\end{tabular}

Observou-se (Figura 5) maior porcentual de áreas com cobertura florestal nativa na região montanhosa (Cocais, com 86\%), comparativamente à área de baixada (Ipaba, com 60\%), indicando que o processo de ocupação antrópica na região de montanhas manteve mais áreas com vegetação nativa, decorrente, principalmente, das dificuldades de cultivo agrícola dos solos.

As áreas com cobertura herbáceo-arbustiva nativa em ambientes pedregosos, em Cocais (2\%) e alagados, em Ipaba (12\%) encontram-se em bom estado de conservação, principalmente devido à impossibilidade de uso agrícola ou florestal e do baixo estoque madeireiro típico dos referidos ambientes. Ademais, essas são áreas de reservas naturais conservadas desde a implantação das plantações de eucalipto. As áreas em processo de recuperação mediante regeneração natural incluem as classes denominadas áreas abertas (AA) e áreas arborizadas (AB), onde a formação de dossel contínuo no estágio inicial normalmente ocorre, em média, em 15 anos, a menos que haja impactos naturais ou antrópicos severos. Outro destaque são os percentuais de áreas com eucalipto e espécies nativas em Cocais (5\%) e em Ipaba (25\%).
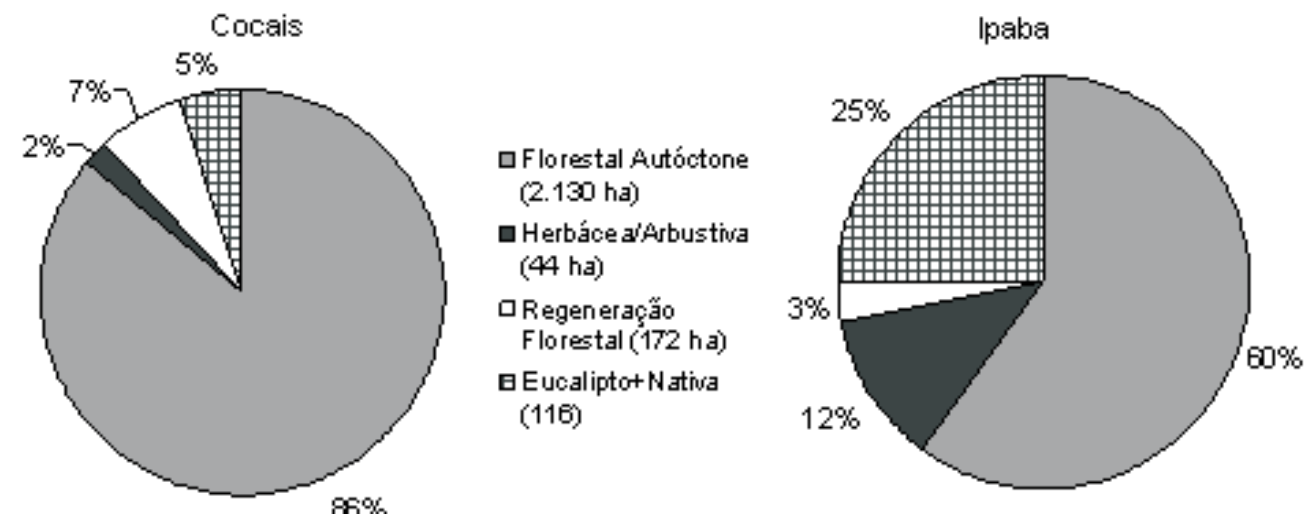

Figura 5 - Relação entre áreas preservadas com cobertura florestal autóctone, com cobertura herbácea/arbustiva autóctone, áreas em regeneração florestal e áreas com eucalipto e espécies nativas, nas áreas de Cocais e Ipaba, Vale do Rio Doce, Estado de Minas Gerais, em 2006.

Figure 5 - Relation between preserved areas with autoctonous forest cover, with herbaceous/shrubby autoctonous cover, areas with forest regeneration and areas with eucalypts and native species, for the area studied of Cocais and Ipaba, Vale do Rio Doce, State of Minas Gerais, Brazil, 2006. 


\subsection{Classes de tamanho}

Verificou-se, pela aplicação do teste de $\chi^{2}$ (GOMES, 1987), igualdade ( $\mathrm{p}<5 \%$ ) entre os números de fragmentos por classes de tamanho nas áreas de montanhas (Cocais) e de baixadas (Ipaba). Entre classes, predominou (Tabelas 3 e 4 e Figura 6AB) o maior número de fragmentos florestais com menos de 5 ha: 69,5\% (169 fragmentos) na região de montanhas (Cocais) e 68,9\% (135 fragmentos) na região de baixadas (Ipaba), perfazendo, em área, apenas $10,1 \%$ e 5,6\% da área total preservada, respectivamente. No outro extremo, os fragmentos maiores que 50 ha, com apenas 4,1\% do número de áreas de reservas em Cocais, representaram 53,3\% da área total de reservas e na região de baixadas, com apenas 4,6\%, perfizeram $67,4 \%$ da área total das reservas. O menor número de fragmentos na maior classe de tamanho ( $\geq 50$ ha), aliado ao maior percentual de áreas de reservas, é um forte indicador de alta conectividade entre os fragmentos de reservas naturais (AMARAL et al., 2009).

Uma análise dos fragmentos florestais nativos na região de Itabira, MG, mostrou que os fragmentos pequenos ( $<5$ ha), alongados e localizados ao longo de cursos d'água, perfizeram $69 \%$ do número total de fragmentos estudados, porém totalizaram somente 31\% das áreas de reservas nativas (SILVA et al., 1997). Resultados de outro estudo realizado no sul

Tabela 3 - Número de fragmentos e área, em hectares, por classes de tamanho dos fragmentos de áreas preservadas inseridos na área de estudo de Cocais, Vale do Rio Doce, Estado de Minas Gerais, Brasil, 2006.

Table 3 - Number of fragments and area, in hectares, by classes of size of the fragments of the preserved areas included in the areas studied in Cocais, Vale do Rio Doce, State of Minas Gerais, Brazil, 2006.

\begin{tabular}{ccccc}
\hline Classe de & \multicolumn{4}{c}{ Fragmentos de Áreas Preservadas } \\
\cline { 2 - 5 } Tamanho (ha) & No de Fragmentos & \% do № de Fragmentos & Área (ha) & \% da Área \\
\hline$\leq 5$ & 169 & 69,5 & 248,53 & 10,1 \\
$>5$ a $\leq 10$ & 25 & 10,3 & 173,70 & 7,1 \\
$>10$ a $\leq 15$ & 18 & 7,4 & 220,73 & 9,0 \\
$>15$ a $\leq 20$ & 7 & 2,9 & 118,78 & 4,8 \\
$>20$ a $\leq 25$ & 5 & 2,1 & 108,10 & 4,4 \\
$>25$ a $\leq 30$ & 5 & 2,1 & 138,18 & 5,6 \\
$>30$ a $\leq 35$ & 3 & 1,2 & 102,42 & 4,2 \\
$>35$ a $\leq 40$ & 1 & 0,4 & 38,45 & 1,6 \\
$>40$ a $\leq 45$ & 0 & 0 & 0 & 0 \\
$>45$ a $\leq 50$ & 0 & 0 & 0 & 0 \\
$>50$ & 10 & 4,1 & $1.313,24$ & 53,3 \\
\hline Total & 243 & 100,0 & $2.462,13$ & 100,0 \\
\hline
\end{tabular}

Tabela 4 - Número de fragmentos e área, em hectares, por classes de tamanho dos fragmentos de áreas preservadas inseridas na área de estudo de Ipaba, Vale do Rio Doce, Estado de Minas Gerais,Brasil, 2006.

Table 4 - Number of fragments and area, in hectares, for classes of size of the fragments of preserved areas inserted in the area of study of Ipaba, Vale do Rio Doce, State of Minas Gerais, Brazil, 2006.

\begin{tabular}{|c|c|c|c|c|}
\hline \multirow{2}{*}{$\begin{array}{c}\text { Classe de } \\
\text { Tamanho (ha) }\end{array}$} & \multicolumn{4}{|c|}{ Fragmentos de Áreas Preservadas } \\
\hline & № de Fragmentos & \% do No de Fragmentos & Área (ha) & \% da Área \\
\hline$\leq 5$ & 135 & 68,9 & 162,71 & 5,6 \\
\hline$>5 \bar{a} \leq 10$ & 22 & 11,2 & 162,66 & 5,6 \\
\hline$>10 \mathrm{a} \leq 15$ & 14 & 7,1 & 178,71 & 6,1 \\
\hline$>15 \mathrm{a} \leq 20$ & 5 & 2,6 & 86,71 & 3,0 \\
\hline$>20 \mathrm{a} \leq 25$ & 2 & 1,0 & 42,87 & 1,5 \\
\hline$>25 \mathrm{a} \leq 30$ & 3 & 1,5 & 84,83 & 2,9 \\
\hline$>30 \mathrm{a} \leq 35$ & 3 & 1,5 & 97,41 & 3,4 \\
\hline$>35 a \leq 40$ & 0 & 0 & 0 & 0 \\
\hline$>40 \mathrm{a} \leq 45$ & 2 & 1,0 & 83,28 & 2,9 \\
\hline$>45$ a $\leq 50$ & 1 & 0,5 & 47,72 & 1,6 \\
\hline$>50$ & 9 & 4,6 & $1.960,30$ & 67,4 \\
\hline Total & 196 & 100,0 & $2.907,20$ & 100 \\
\hline
\end{tabular}

Revista Árvore, Viçosa-MG, v.34, n.4, p.733-743, 2010 

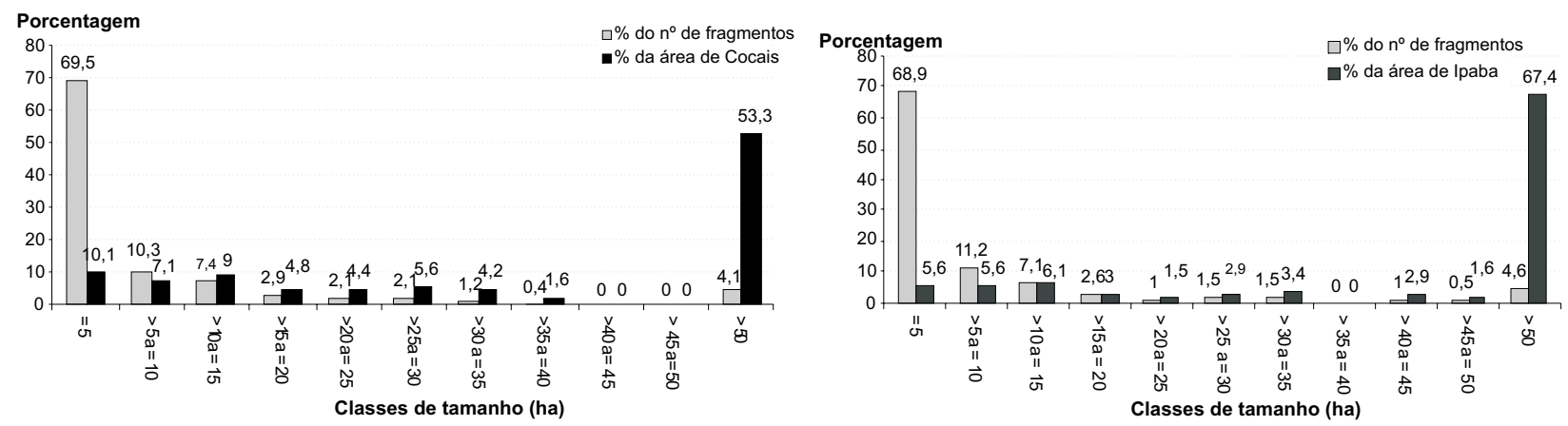

Figura 6 - Distribuição da classificação por classe de tamanho nas áreas preservadas: (A) Cocais; e (B) Ipaba, Vale do Rio Doce, Estado de Minas Gerais, Brasil, 2006.

Figure 6 -Distribution of the classification by size classes for the preserved areas: (A) Cocais; and (B) Ipaba, Vale do Rio Doce, State of Minas Gerais, Brazil, 2006.

da Bahia, Município de Eunápolis, BA, na região dos vales (tabuleiros), mostraram que os fragmentos pequenos ( $<5$ ha), alongados e circunvizinhos a cursos d’água, na maioria em estágio inicial de regeneração (49\%), totalizaram 75\% do número total de áreas de reservas nativas, porém perfizeram somente $30 \%$ da área total preservada (OLIVEIRA et al., 1997). No bioma Floresta Atlântica, a predominância de fragmentos florestais nativos pequenos e de forma alongada e com alta relação perímetro/área tende a ser o padrão geral dos remanescentes florestais (GREGGIO et al., 2009; CEMIN et al., 2009).

\section{CONCLUSÕES}

As ilustrações na forma de perfil, com escalas vertical e horizontal, são eficientes e podem ser utilizadas para representação e diferenciação das fitofisionomias dos estágios de sucessão da Floresta Atlântica e de outros ecossistemas e facilitam a interpretação de leis aplicadas ao assunto.

Predominam, na região montanhosa (86,5\%) e na região de baixadas (59,8\%), áreas de preservação permanente e de reserva legal com cobertura florestal nativas. A região montanhosa apresentou cerca de 52\% de reservas de florestas nativas em estágio inicial e 31\% em estágio médio. Já a região de baixadas apresentou aproximadamente 23\% de estágio inicial e 33,4\% de estágio médio.

Embora predominem ecossistemas florestais, as áreas em melhor estado de conservação são os ecossistemas com cobertura herbácea/arbustiva autóctones, que em Cocais correspondem aos locais com afloramentos rochosos e, em Ipaba, às áreas alagadas. Isso se deve, sobretudo, à inexistência de estoque madeireiro e à impossibilidade do uso do solo para agricultura ou silvicultura nesses locais.

Predominou nas regiões planas e montanhosas o maior número de áreas de reservas menores que 5 ha, que representaram pequena porcentagem da área de reservas. O menor número de fragmentos na maior classe de tamanho ( $>50$ ha), aliado ao maior percentual de área preservada, é um forte indicador de alta conectividade entre os fragmentos de reservas naturais.

\section{REFERÊNCIAS}

AMARAL, M. V. F. et al. Dinâmica da cobertura vegetal (1980-2004) em um projeto de produção florestal, nos municípios de Bugre e Ipaba, MG. Revista Árvore, v.33, n.2, p.315-325, 2009.

BATISTELLA, M.; ROBESON, S.; MORAN, E. F. Settlement design and landscape change in Amazônia: a multi-temporal evaluation using spatial metrics. Photogrammetric Engeneering and Remote Sensing, v.69, n.7, p.805-812, 2003.

BRASIL. Resolução/CONAMA no ${ }^{\circ}$, de 1 de outubro de 1993. Estabelece parâmetros para análise dos estágios de sucessão da Mata Atlântica. Brasília, 1993. Diário Oficial da República Federativa do Brasil, de 3/11/1993. 
BRASIL. Resolução/CONAMA nº 392, de 25 de junho de 2007. Define vegetação primária e secundária de regeneração de Mata Atlântica no Estado de Minas Gerais. Diário Oficial da República Federativa do Brasil, de 26/06/2007.

BROWN, L. R.; LARSEN, J.; FISCHLOWITZROBERTS, B. The earth policy reader. New York: WW North, 2002. 192p.

CAIRNS JR., J. Sustainability and the anthropogenic alteration of evolutionary processes. Ethics in Science and Environmental Politics ESEP n.5, p.65-68, 2004.

CALEGÁRIO, N. et al. Parâmetros florísticos e fitossociológicos da regeneração natural de espécies nativas no sub-bosque de povoamentos de eucaliptos. Revista Árvore, v.17, n.1, p.16-29, 1993.

COMPANHIA ENERGÉTICA DO ESTADO DE MINAS GERAIS - CEMIG. Levantamento Aerofotogramétrico, 1986.

CEMIN, G.; PERICO, E.; REMPEL, C. Composição e configuração da paisagem da sub-bacia do Arroio Jacaré, Vale do Taquari, RS, com ênfase nas áreas de florestas. Revista Árvore, v.33, n.4, p.705-711, 2009.

ECOA CONSULTORIA LTDA. Estudo de impactos ambientais do processo silvicultural da Celulose NipoBrasileira S.A. - CENIBRA. 2002. 402 p. (Documento não publicado).

ESPIRITO-SANTO, F. B. et al. Análise da composição florística e fitossociológica da florestal nacional do Tapajós com apoio geográfico de imagens de satélites. Acta Amazônica, v.35, n.2, p.155-173, 2005.

\section{ENVIRONMENTAL SYSTEMS RESEARCH} INSTITUTE - ESRI. Sistema de informação geográfica. ArcView GIS., v.9. Redlands. CA. CD-ROM, 2004.

FERREIRA, R. L. C.; SOUZA, A. L.; SILVA, A. F. Dinâmica da estrutura de uma floresta secundária de transição. III. Estrutura horizontal. Revista Árvore, v.23, n.2, p.157-168, 1999.

Revista Árvore, Viçosa-MG, v.34, n.4, p.733-743, 2010
GOMES, F. P. Curso de estatística experimental. 12.ed. Piracicaba: Nobel, 1987. 467p.

GREGGIO, T. C.; PISSARRA, T. C. T.; RODRIGUES, F. M. Avaliação dos fragmentos florestais do município de Jaboticabal-SP. Revista Árvore, v.33, n.1, p.117-124, 2009.

HIGMAN, S. et al. The Sustainable Forestry Handbook. 2.ed. London: The Earthscan Forestry Library, 2005. 332p.

FUNDAÇÃO INSTITUTO BRASILEIRO DE GEOGRAFIA E ESTATÍSTICA - IBGE. Mapa de vegetação do Brasil. Rio de Janeiro: Ministério do Planejamento Orçamento e Gestão, 2004. I mapa, color, Escala 1:5.000.000.

LANA, J. M. Ecologia da paisagem de Mata Atlântica na Bacia do Rio Doce, Estado de Minas Gerais. 2006. 116f. Dissertação (Mestrado) - Universidade Federal de Viçosa, Viçosa, MG, 2006.

MARTINS, I. C. M. et al. Diagnóstico ambiental no contexto da paisagem de fragmentos florestais naturais “Ipiucas” no município de Lagoa da Confusão, Tocantins. Revista Árvore, v.26, n.3, p.299-309, 2002.

METZGER, J. P. Estrutura da paisagem e fragmentação: análise bibliográfica. Anais da Academia Brasileira de Ciências, v.71, p.445-463, 1999.

MINAS GERAIS. Deliberação Normativa n. 74, de 09 de setembro de 2004. Diário Oficial de Minas Gerais. Belo Horizonte, 2004.

NASCIMENTO, M. C. et al. Mapeamento dos fragmentos de vegetação nativa na bacia hidrográfica do Rio Alegre, Espírito Santo, a partir de imagens do satélite IKONOS II. Revista Árvore, v.30, n.3, p.389-398, 2006.

NAVE, A. G. Determinação de unidades ecológicas num fragmento de floresta nativa, com auxílio de sensoriamento remoto. 1999. 167f. Dissertação (Mestrado em Ciências Florestais - ESALQ/USP) - Escola Superior de agricultura Luiz de Queiroz, Piracicaba, 1999. 
OLIVEIRA, L. M. T. et al. Diagnostico de fragmentos florestais nativos, em nível de paisagem, Eunápolis- BA. Revista Árvore, v.21, n.4, p.501-510, 1997.

PONZONI, F. J.; REZENDE, A. C. P. Influência da resolução espacial de imagens orbitais na identificação de elementos da paisagem em AltamiraPA. Revista Árvore, v.26, n.4, p.403-410, 2002.

SAYRE, R. et al. Natureza em foco: avaliação ecológica rápida. The Nature Conservancy.

Arlington: 2003. 175p.

SILVA, E. et al. Diagnóstico de fragmentos florestais nativos, em nível de paisagem, ItabiraMG. Revista Árvore, v.21, n.4, p.511-520, 1997.
SOUZA, P. B. et al.. Florística e estrutura da vegetação arbustivo-arbórea do sub-bosque de um povoamento de Eucalyptus grandis W. Hill ex Maiden em Viçosa, MG, Brasil. Revista Árvore, v.31, n.3, p.533-543, 2007.

SOUZA, A. L. et al. Dinâmica da composição florística de uma floresta ombrófila densa secundária, após corte de cipós, Reserva Natural da Companhia Vale do Rio Doce S.A., Estado do Espírito Santo Brasil, Revista Árvore, v.26, n.5, p.549-558, 2002.

VELOSO, H. P.; RANGEL FILHO, A. L. R.; LIMA, J. C. A. Classificação da vegetação brasileira, adaptada a um sistema universal. Rio de Janeiro: Instituto Brasileiro de Geografia e Estatística (IBGE), 1991. 123p. 